\title{
Ogmentasyon Sistoplasti
}

\author{
Mansur Dağgülli \\ Dicle Üniversitesi Tıp Fakültesi, Üroloji Anabilim Dalı, Diyarbakır, Türkiye
}

\section{Giriş}

Ogmentasyon sistoplasti geçmişi, 1950'lere dayanan ve o dönemde sadece tüberküloza bağlı kontrakte mesanesi olan hastalara uygulanan bir cerrahi yöntem olarak ortaya çıkmıştır (1). Clam sistoplasti olarakta bilinen ogmentasyon sistoplastisi mesanenin kapasitesini artırmak amacıyla yapılan bir cerrahidir (2). Bu cerrahinin primer amacı mesane kapasitesini artırarak kompliyansta iyileşme sağlamak ve intravezikal basıncı düşürerek böbrekleri yüksek basınçtan ve reflüden korumaktır. Konzervatif yöntemlerin ve medikal tedavinin başarısız olduğu, kompliyansı azalmış ve hiperrefleksiv mesanesi olan nörojen mesaneli hastalara, ogmentasyon sistoplasti yapılmakta ve başarılı sonuçlar bildirilmiştir (3-5). Ogmentasyon sistoplastisi üst üriner sistemi reflüden ve yüksek intravezikal basınçtan korumak için mesane kapasitesini artırmak amacıyla yapılan bir rekonstürüksiyon tekniğidir. Lapides ve ark. (6) 1972 yılında temiz aralıklı kateterizasyon (TAK) kavramını ortaya atması ogmentasyon sistoplasti için bir dönüm noktası olmuştur.

En sık spina bifidaya bağlı olarak ortaya çıkan; medikal tedaviye dirençli nörojenik detrüsör hiperaktivitesinde ogmentasyon sistoplasti endikedir. Pelvik radyasyon ya da intravezikal kemoterapiden kaynaklanan mesane kompliyansı azalmasında, ayrıca interstisyel sistit gibi inflamatuar bir nedenden dolayı ya da tüberküloz ve şistozoma gibi bir nedenden dolayı gelişen kontrakte mesane durumunda da ogmentasyon sistoplasti endikedir. Ogmentasyon sistoplastinin başarısında hasta seçimi önemli bir yere sahiptir. Kateterizasyon yapamayacak durumda olan hastalar bu işlem için uygun aday değildir. Çünkü Post operatif olarak nörojen mesanesi olmayan hastalarda bile \%39 ile \%89 arasında TAK gereksinimi olmaktadır (7,8). Multiple skleroz ve demans gibi ilerleyici nörolojik ya da bilişsel hastalığı olan hastalar, TAK yapabilme yeteneklerini zamanla kaybedecekleri için ogmentasyon sistoplasti için uygun aday değildirler.

\section{Hasta Hazırlığı ve Cerrahi Teknik}

Ogmentasyon sistoplastisi operasyonu öncesi tüm hastaların idrar kültürü ile değerlendirilmesi önerilmektedir. Üst üriner sistemi değerlendirmek için böbrek ultrasonografisi, intravenöz piyelografi, mesaneyi değerlendirmek için ise ürodinamik inceleme ve sistoskopik inceleme yapılmalıdır. Operasyondan birkaç gün öncesinde sıvı diyete başlanılmalıdır. Ogmentasyon için bağırsak segmenti olarak ileum kullanılacaksa mekanik bağırsak temizliğine ihtiyaç yoktur. Fakat kolon kullanılacaksa mekanik bağırsak temizliğine ihtiyaç vardır (9).

Ogmentasyon sistoplastisi için mide, ileum, çekum ve kolon kullanılabilir (10). Geniş pelvik radyoterapi uygulanmış hastalarda ince bağırsak kullanımı uygun değildir. Kolon kanseri, divertikülit ya da ülseratif kolit öyküsü varlığında ise kalın bağırsak kullanılmamalıdır. Geçirilmiş cerrahi ya da crohn hastalığı öyküsü varsa özellikle bağırsak rezeksiyonunun emilimi ciddi oranlarda bozulabileceği için bağırsak segmenti kullanarak ogmentasyon sistoplasti yapılması kontrendikedir (11).

Bağırsak segmentlerinin kompliyansı, mukus üretimi ve elektrolit geçirgenliği farklıdır. Bağırsak segmenti seçilirken, bu faktörlerin ve hastanın preoperatif durumunun gözönünde bulundurulması gereklidir. ileum en sık kullanılan bağırsak segmentidir. Yaklaşık 20-35 cm uzunluğundaki bir ileum segmenti mezenterial damarlar korunarak elde edilir (12). illeoçekal valvin 15-20 cm proksimalinden alınan ve ogmentasyon için detübülarize edilen ileum segmenti düşük basınç sağlamakta, daha az miktarda mukus salgılamakta ve tüm bağırsak segmentleri içinde en az metabolik bozukluğa yol açmaktadır $(1,13)$. Supratrigonal sistektomi sonrası substitüsyon için büyük bir rezervuar sağladığından çekum kullanılabilir. Mezenterin kısa olması, adezyon yada geçirilmiş bağırsak cerrahisi sebebiyle ileum kullanılamadığında sigmoid kolon ogmentasyon için bir seçenek olabilir. Geniş lümenli olması, kapasitesinin fazla olması, ra- 
hatlıkla ulaşılabilmesi ve düşük basınçlı olması sigmoid kolon kullanmanın avantajları arasında sayılabilir. Fakat sigmoid sistoplastinin mukus üretiminin daha fazla olması, enfeksiyona yatkınlık ve uzun dönem malignensi gibi dezavantajları da vardır. Mesane ogmentasyonu yapılacak olan bir hastada mide ilk seçenek olmamalıdır. Mide, ogmentasyon için sadece böbrek yetmezliği olan çocuklarda ve mesaneye radyasyon almış erişkinlerde kullanılabilir (13).

Ogmentasyon için ileum kullanılacaksa phannenstiel insizyonu uygun olabilir. Ancak bağırsağın hangi segmentinin kullanılacağı operasyon esnasında netleştiği için daha iyi bir görüş sağlayan orta hat insizyonu, ogmentasyon sistoplasti için daha uygundur. Peritona girildikten sonra mesanenin belirgin hale gelmesi için izotonikle doldurulur. Peritonla mesane arası önde mesane boynu arkada trigon seviyesine gelene kadar diseke edilmelidir (Resim 1) (14). Farklı sistotomi insizyonları tarif edilsede en sık kullanılanlardan birisi; mesanenin arka kısmında kubbeye yakın yerden tabanı önde olan ve arkaya doğru $U$ şeklinde uzanan bir mesane insizyonu ile sistotomi yapılmasıdır (Resim 2). Bu şekilde mesane kubbeden açılmış olur. Bu tür sistotomi ile mesane kas tabakasında büyük oranda hasar meydana getirilerek bağırsak ile anastomoz için yeteri uzunlukta mesafe sağlanır. Başka bir sistotomi tipinde ise mesanenin sagital olarak yani orta hattan dikine bir şekilde insize edilir. Kockelbergh ve ark. (15) 45 hasta üzerinde yaptıkları bir çalışmada (19'u koronal ve 26'sı sagittal) sagittal enterosistoplastinin, coronal enteroplastiye göre daha kolay uygulandığını bildirmişlerdir.

Ileumun kompliyansı çok yüksek olduğundan dolayı ileal segmentin uzunluğu mesanedeki yapılacak insizyona bağlıdır. Seçilen bağırsak segmentine göre detübülarizasyon işlemi gerekebilir. İleum kullanılacağı zaman detübülarizasyon işlemi gerekir. Detübülarizasyon işlemi bağırsak segmentinin kontraksiyonlarını önlemek için yapılır. Ogmentasyon için gerekli olan ileum uzunluğu, post operatif dönemlerde 4 saatte bir kateterizasyona yetebilecek uzunlukta olmalıdır. Distal ileumun 15-20 cm'lik kesimi korunarak, mesaneye kolayca ulaşabilecek segment işaretlenir (Resim 3) (14). Seçilen yaklaşık 20-30 cm'lik bağırsak segmenti mezenterial damarları korunarak eksize edilir. illeumun devamlılığı stapler veya sütür kullanılarak sağlanabilir. Mezenter defektide uçuca sütüre edilerek kapatılır (Resim 4) (14). Alınan bağırsak segmentinin lümeni irrige edilerek temizlendikten sonra antimezenterik yüzeyinden koterle tam kat açוlır. Detübülarizasyon için alınan segment $U$ haline getirilerek öncelikle arka duvar daha sonra ön duvarı kendi üzerinde kontinue olarak dikilir $\left(\mathrm{Re}^{-}\right.$
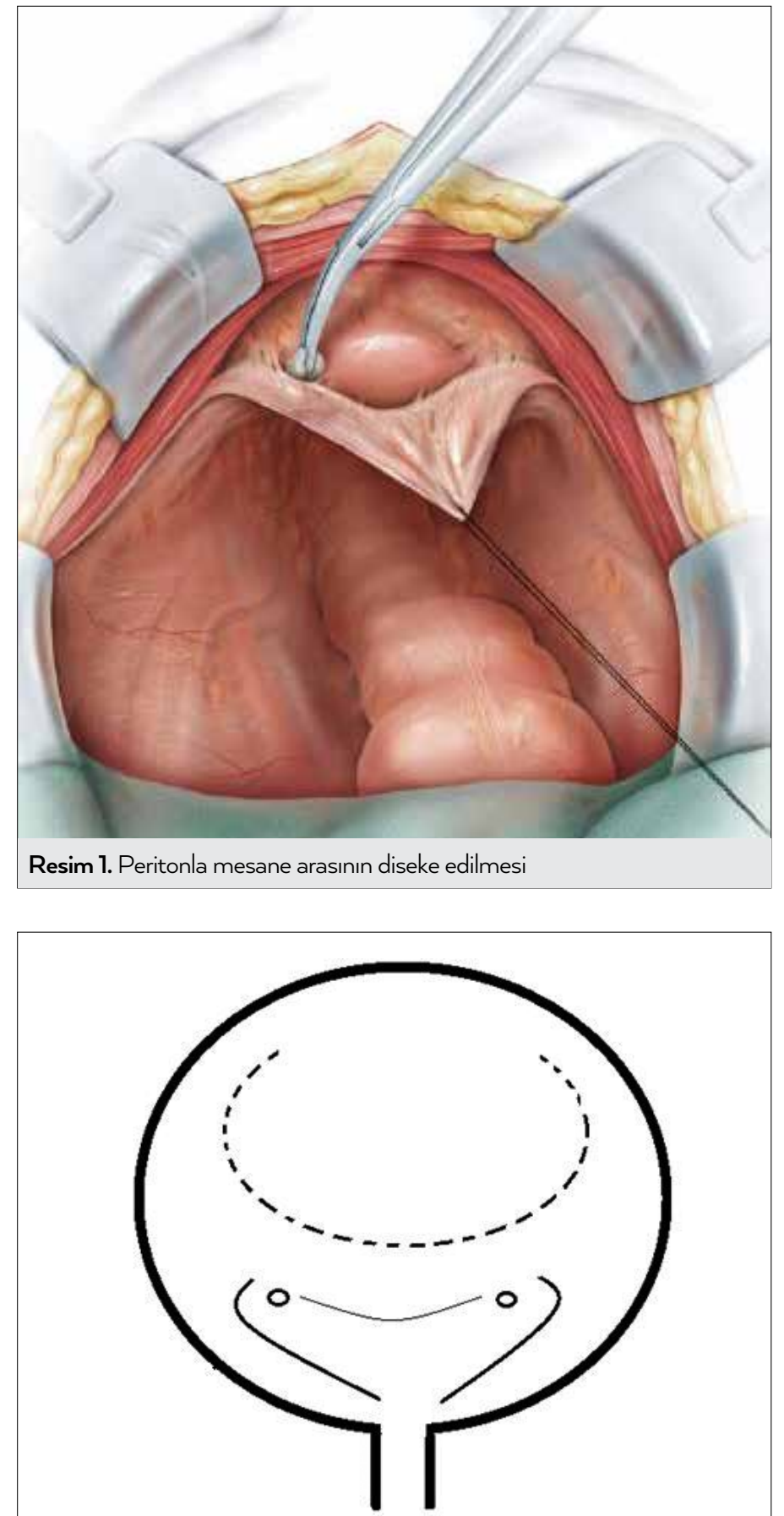

Resim 2. Mesanenin arka kısmında kubbeye yakın yerden tabanı önde olan ve arkaya doğru $U$ şeklinde uzanan bir mesane insizyonu ile sistotomi yapılması

$\operatorname{sim} 5$ ) (14). Ön duvar mesanede oluşturulan sistotominin uzunluğuna göre kapatılmalıdır. Bağırsak ile mesane anastomozu tamamen kapatılmadan önce yeteri kadar iyileşme sağlanıncaya kadar oluşabilecek mukusun irrigasyonunu ve drenajın sağlanması amacıyla mesane duvarından geçecek şekilde geniş lümenli bir suprapubik kateter ögmente edile- 

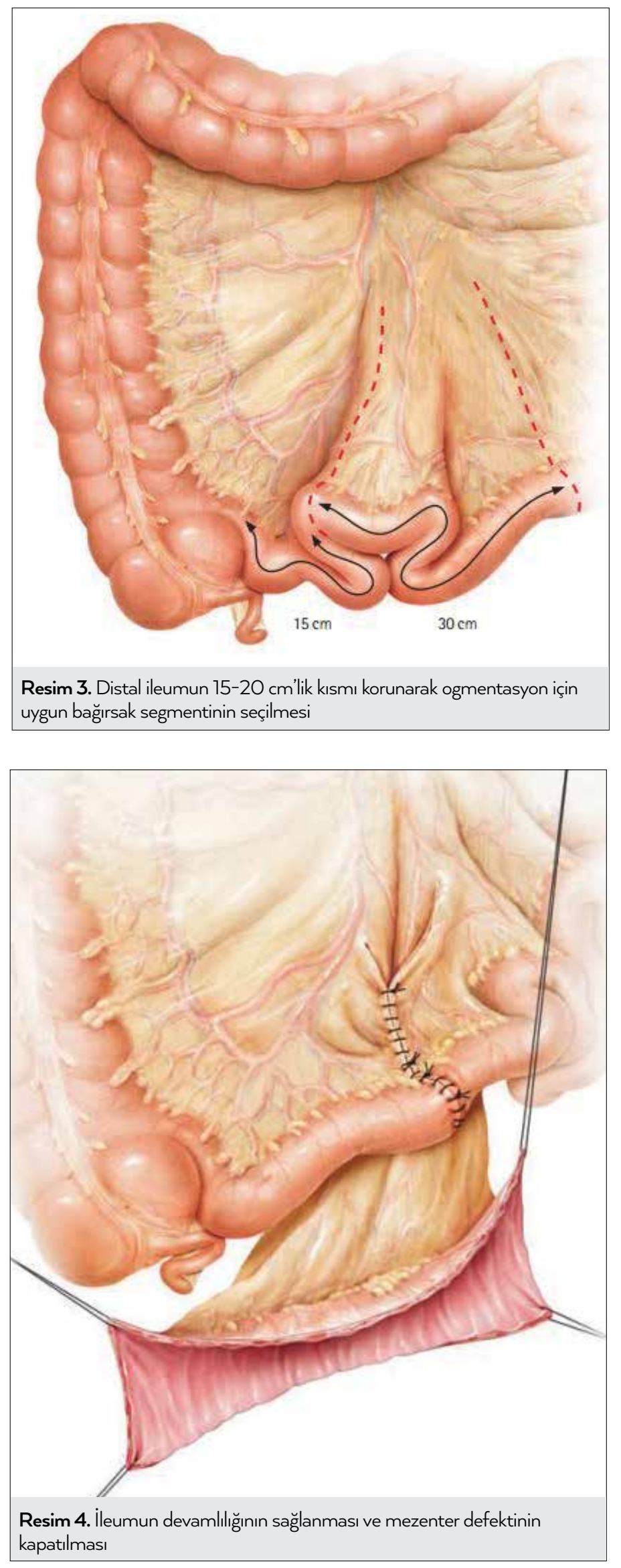

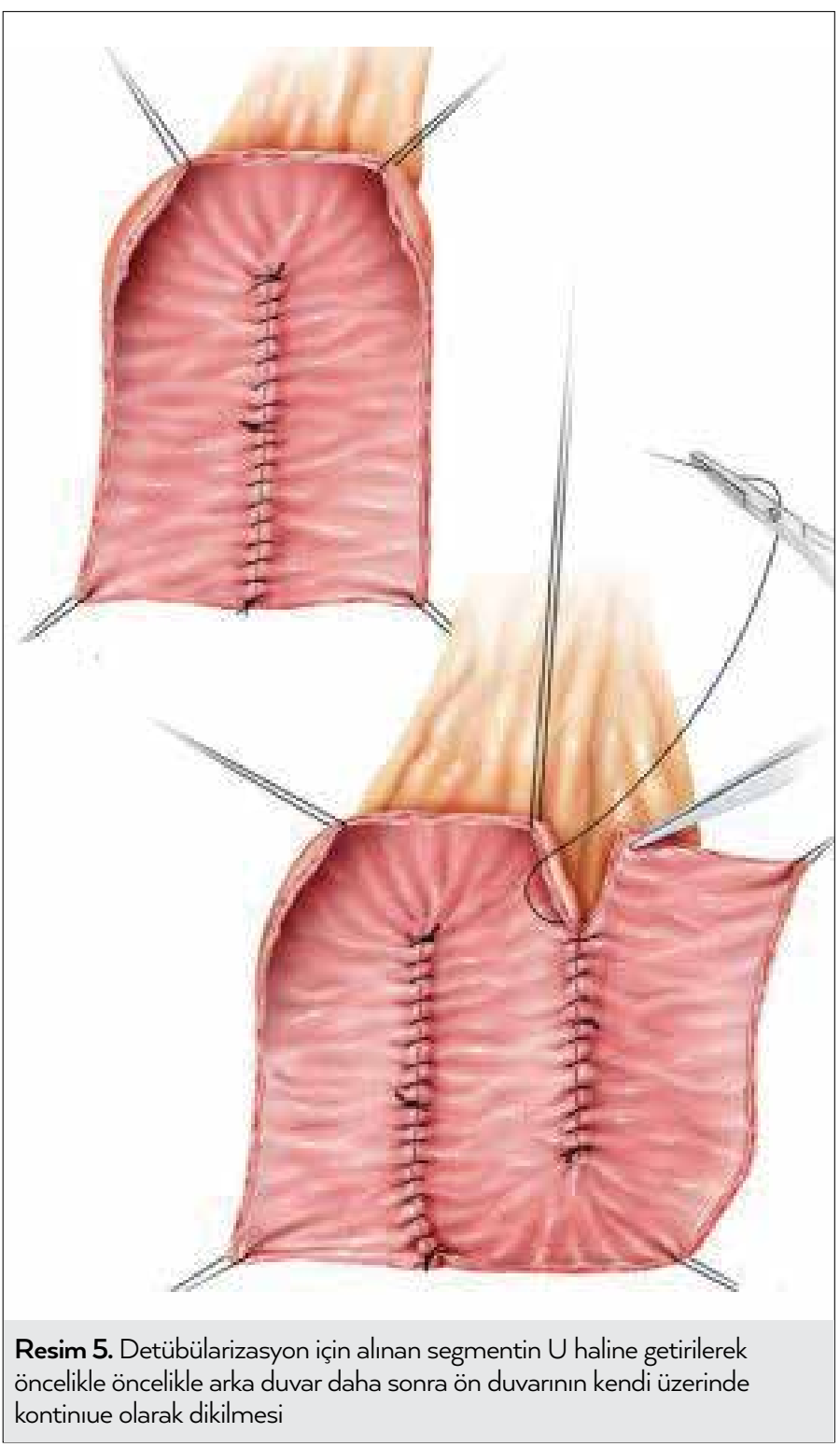

cek bağırsak segmentinin içine yerleştirilir. Kullanılacak sütur materyalleri geç emilen, mesanenin ve bağırsağın gerilimsiz olarak tam kat sütüre edildiği su sızdırmaz tarzda olmalıdır.

\section{Postoperatif Bakım}

Enterosistoplasti cerrahi sonrası sıvı elektrolit takibi ve tedavisi önemlidir. Post operatif dönemde mesane içinde birikebilecek mukusu temizlemek için suprapubik konulan kateterden düşük basınçla günde 4-5 kez irrigasyon yapılmalıdır. Post operatif 3. haftada çekilen sistografi de ekstravazasyon yoksa TAK başlanabilir. Suprapubik kateter yerleştirilmişse yeteri kadar TAK kullanma becerisi kazanana kadar kateter klemplenip beklenilebilir. Genellikle ilk altı ay gece iki kez ve gündüzde 3 saatte bir olmak üzere sık aralıklarla TAK yapılmalıdır. Illk bir yıl dolduktan sonra ogmentasyon maksimun kapasitesine erişeceğinden 
dolayı sık aralıklı TAK uygulaması azaltılabilir. Post op ilk bir yıl boyunca hasta, sık aralıklarla TAK yapmakta sıkıntı yaşayabileceği için hastaya antikolinerjik tedavi verilebilir. Operasyon sonucunda mesane kapasitesi arttıkça hastanın TAK gereksinimi giderek azalacaktır. Üretradan idrar yapabilen hastalara TAK kullanmayı bırakmadan önce postvoiding rezidü idrar bakılmalıdır. Çünkü rezidünün fazla olması perforasyonla sonuçlanabilmektedir. Ayrıca düzenli aralıklarla biyokimyasal açıdan hastalar değerlendirilmeli ve üst üriner sistem dilatasyon açısından takip edilmelidir. Kullanılan bağırsak segmentine göre gelişebilecek metabolik problemler ve vitamin eksikleri de göz önünde bulundurulmalıdır.

\section{Komplikasyonlar}

Gastrointestinal segmentler mesane replasmanı ve ogmentasyonu için sık olarak kullanılır. Ancak, gastrointestinal doku ve idrar arasındaki temas çeşitli erken ve geç dönem komplikasyonlara neden olabilir (16). Erken dönem komplikasyonları arasında tromboembolizm ve bağırsak obstruksiyonu, geç dönem komplikasyonları arasında ise mesane perforasyonu, inkontinans, metabolik bozukluk, bakteriüri, taş ve ogmentasyon için alınan segmentte karsinom gelişmesi sayılabilir (Tablo 1) (2). Flood ve ark. (7) ogmentasyon yapılan 122 hastayı dahil ettikleri bir çalışmada \%28 oranında erken dönem ve \%44 oranında geç dönem komplikasyon görüldügünü bildirmişlerdir.

Ogmentasyon için alınan bağırsak segmentinde zamanla gelişecek olan villus atrofisine rağmen mukus üretimi tamamen kesilmez. Mukus birikimi drenaj bozukluğuna, enfeksiyona ve içerisinde taş oluşumuna zemin hazırlamaktadır (17). Ogmentasyon sistoplasti sonrası sık görülen (\%40) komplikasyonlardan biri de mesane taşı oluşumudur (10). Mesanenin sık aralıklarla irrigasyonu ve enfeksiyonun engellenmesi taş oluşumunu önemli oranlarda azaltacaktır.

Çoğunlukla idrar kültüründe üreme olacağından TAK kullanan hastalarda rutin idrar kültürü takibi yapılmasına gerek yoktur. Mevcut üremenin enfeksiyon olarak değerlendirilebilmesi için hastanın kliniğinin semptomatik olması gerekir. Bakteriürinin \%75 oranında gösterildiği bir çalışmada \%20'sinde semptomatik üriner sistem enfeksiyonu geliştiği gösterilmiştir (18).

Spontan mesane perforasyonu, mortalite ile sonuçlanabilen hayatı tehdit eden bir komplikasyonudur. Metcalfe ve ark. (19) yaptıkları bir çalışmada ogmentasyon sistoplasti yapılan 500 hastanın, 43 'ünde spontan mesane perforasyon geliştiğini bildirilmişlerdir. Klinik olarak şüphe duyulduğunda hastalar dolu ve boş mesane ile çekilecek sistografi ile değerlen-

\begin{tabular}{l|c}
\hline Tablo 1. Mesane ogmentasyon komplikasyonları \\
\hline Erken dönem komplikasyonlar & Etkilenen hasta (\%) \\
Bağırsak obstrüksiyonu & 2 \\
Enfeksiyon & 1,5 \\
Tromboemboli & 1 \\
Kanama & 0,75 \\
Fistül & 0,4 \\
Geç dönem komplikasyonları & Etkilenen hasta (\%) \\
Temiz aralıklı kateterizasyon & 38 \\
Üriner trakt enfeksiyonu & 70 (asemptomatik) \\
& 20 (semptomatik) \\
Üriner sistem taşı & 13 \\
Metabolik rahatsızlık & 16 \\
Renal fonksiyon bozukluğu & 2 \\
Mesane perforasyonu & 0,75 \\
Mesane semptomlarında değişiklik & 25 \\
\hline
\end{tabular}

dirilmeli eğer perforasyon varsa açık cerrahi girişim yapılarak perforasyon onarılmalıdır.

Bağırsakların iç yüzeyi elektrolitlerin emiliminden ve salınımından sorumludur. sistoplasti sonrası hastalarda yağ malabsorbsiyonu ve diyare gelişebilir. Seçilen bağırsak segmentinin yeri, uzunluğu, idrarla temas süresi ve hastanın renal fonksiyonuna göre metabolik bir bozukluğa yol açabilir. Illeum ve kolon kullanılmasına bağı olarak bikarbonat kaybı, hipokalemik ve hiperkloremik metabolik asidoz ortaya çıkabilir. Metabolik asidoz devam etmesi durumunda oral bikarbonat ile müdahale edilebilir. Ogmentasyon için mide kullanılması durumunda ise metabolik alkaloz meydana gelir. Bu durum midenin çocuklarda ve kronik böbrek rahatsızlığı olanlarda tercih edilmesini sağlar. Böbrek fonksiyonlarında azalma olan hastalar yakın takip edilmelidir. Bu yönden hastalar en az yılda bir kez kontrol edilmelidir (20). Post operatif dönemde intravezikal basıncın yüksek seyretmesi durumunda, gelişen reflüye ve geçirilen üriner sistem enfeksiyonlarına bağlı olarak böbrek fonksiyon kayıpları meydana gelebilir.

Bağırsak segmentlerinin kullanımı sonucunda, tümör gelişebileceği bildirilmiştir. Kanser gelişimi için uzun yılların geçmesi gerekir. Ogmentasyon yapılmış mesanede malignite riski \%1,2 civarında tahmin edilmektedir Transizyonel hücreli karsinom bildirilmiş olmasına rağmen gelişen tümörler adenokarsinom olma eğilimindedir. Otuz yıl önce ogmentasyon sistoplasti yapılmış olan bir hastada intestinal adenokarsi- 
nom geliştiği bildirilmiştir. Bu yüzden operasyondan 10 yıl sonra yıllık sistoskopi yapılması önerilmektedir (21). Malignite riskinin mide ile yapılan ogmentasyonda en yüksek olduğu gösterilmiştir (22). Ogmentasyon sistoplasti sonrası oluşabilecek komplikasyonlardan biri de fistül gelişimidir. Yedi yıl önce ogmentasyon sistoplasti yapılmış bir hastada ise kolovezikal fistül geliştiği bildirilmiştir (23).

\section{Sonuç}

Nörojenik ve non-nörojenik mesane disfonksiyonu olan hastalarda konservatif tedaviler, farmakolojik tedavi yöntemleri ve minimal invaziv tedaviler başarısız ve yetersiz olduğunda ogmentasyon sistoplastisi yüksek hasta memnuniyeti oranları ile bir seçenek olarak ön plana çıkmaktadır $(1,24)$. Ogmentasyon sistoplastinin alt üriner sistemin disfonksiyonunda ve üst üriner sistemin dilatasyondan korunmasında oldukça etkili ve güvenli olduğu gösterilmiştir. Gurung ve ark. (25) spinal kord hasarı olan hastalarda yapılan ogmentasyon sistoplastinin intravezikal basıncı düşürmede oldukça etkili olduğunu bildirmişlerdir. Bir başka çalışmada Liao ve ark (26). nörojenik mesanesi olan ve ogmentasyon yapılan, 120 hastayı içeren çalışmalarında postoperatif altıncı ayda ürodinamik incelemede önemli derecede düzelme olduğu, 36 aylık takip sonunda hasta memnuniyetinin yüksek olduğunu belirtmişlerdir. Hasan ve ark. (5) idiopatik detrusor anstabilitesi nedeniyle ogmentasyon sistoplastisi yapılan 48 hastanın postoperatif sonuçlarını değerlendirdikleri çalışmalarında 36 (\%75) hastada TAK gerektiğini bildirmişlerdir.

Ögmente yapılan segmentte devam eden peristaltizmler mesane içerisinde yüksek basınca neden olarak inkontinansa neden olabilir. Pope ve ark. (27) enterosistoplasti yapılan 323 hastayı içeren çalışmalarında \%5,9 hastada intravezikal yüksek basıncın devam ettiğini tespit etmişlerdir. Mesanede kontraktilite devam edebileceği için antikolinerjik tedavi verilmesi uygun olacaktır.

Ogmentasyon sistoplastinin interstisyel sistiti olan hastalardaki sonuçları yüz güldürücü değildir. Blaivas ve ark. (28) bening nedenlerle ogmentasyon sistoplasti yapılan 76 hastayı içeren çalışmalarında; intersitisyel sistiti olan 7 hastanın hiçbirisinin bu operasyondan fayda görmediğini aksine detrusor hiperaktivitesi olan hastaların ise tamamının fayda gördüğünü bildirmişlerdir.

Sonuç olarak konservatif tedavi ve minimal invaziv tedavi yöntemlerinden fayda görmeyen, seçilmiş uygun hastalara ogmentasyon sistoplasti ameliyatı uygun bir seçenektir.

\section{Kaynaklar}

1. Bramble FJ. The treatment of adult enuresis and urge incontinence by enterocystoplasty. Br J Urol 1982; 54: 693-6. [CrossRef]

2. European Association of Urology Guidelines. Update March 2015.

3. Rahmi Onur, Ömer Bayrak. Üriner inkontinans tanı ve tedavi. İstanbul, Ogmentasyon, sayfa: 281.

4. Herschorn S, Hewitt RJ. Patient perspective of long-term outcome of augmentation cystoplasty for neurogenic bladder. Urology 1998; 52: 672-8. [CrossRef]

5. Hasan ST, Marshall C, Robson WA, Neal DE. Clinical outcome and quality of life following enterocystoplasty for idiopathic detrusor instability and neurogenic bladder dysfunction. Br J Urol 1995; 76: 551-7. [CrossRef]

6. Lapides J, Diokno AC, Silber SJ, Lowe BS. Clean, intermittent self-catheterization in the treatment of urinary tract disease. J Urol 1972; 107: 458-61.

7. Flood HD, Malhotra SJ, O'Connell HE, Ritchey MJ, Bloom DA, McGuire EJ. Long-term results and complications using augmentation cystoplasty in reconstructive urology. Neurourol Urodyn 1995; 14: 297-309. [CrossRef]

8. Juhasz Z, Somogyi R, Vajda P, Oberritter Z, Fathi K, Pinter AB Does the type of bladder augmentation influence the resolution of pre-existing vesicoureteral reflux? Urodynamic studies. Neurourol Urodyn 2008; 27: 412-6. [CrossRef]

9. Gundeti MS, Godbole PP, Wilcox DT. Is bowel preparation required before cystoplasty in children? J Urol 2006; 176: 1574-6. [CrossRef]

10. Biers SM, Venn SN, Greenwell TJ. The past, present and future of augmentation cystoplasty. BJU Int 2012; 109: 1280-93. [CrossRef]

11. Rackley RR, Ross JH, Abdelmalak J. Augmentation cystoplasty: open and laparoscopic approaches. Textbook of reconstructive urologıc surgery, Montague D, Gill I, Angermeier K, Ross JH. London, Informa Healthcare 2008; 289-95. [CrossRef]

12. Veeratterapillay R, Thorpe AC, Harding C. Augmentation cystoplasty: Contemporary indications, techniques and complications. Indian J Urol 2013; 29: 322-7. [CrossRef]

13. Hendren WH, Hendren RB. Bladder augmentation: Experience with 129 children and young adults. J Urol 1990; 144: 445-53.

14. Stein R, Kamal MM, Rubenwolf P, Ziesel C, Schröder A, Thüroff JW. Bladder augmentation using bowel segments (enterocystoplasty). BJU Int 2012; 110: 1078-94. [CrossRef]

15. Kockelbergh RC, Tan JB, Bates CP, Bishop MC, Dunn M, Lemberger RJ. Clam enterocystoplasty in general urological practice. $\mathrm{Br} J$ Urol 1991; 68: 38-41. [CrossRef]

16. Atala A. New methods of bladder augmentation. BJU Int 2000; 85: 24-34. [CrossRef]

17. Khoury AE, Salomon M, Doche R, Soboh F, Ackerley C, Jayanthi R, et al. Stone formation after augmentation cystoplasty: the role of intestinal mucus. J Urol 1997; 158: 1133-7. [CrossRef]

18. Greenwell TJ, Venn SN, Mundy AR. Augmentation cystoplasty. BJU Int 2001; 88: 511-25. [CrossRef]

19. Metcalfe PD, Casale AJ, Kaefer MA, Misseri R, Dussinger AM, Meldrum KK, et al. Spontaneous bladder perforations: a report of 500 augmentations in children and analysis of risk. J Urol 2006; 175: 1466-70. [CrossRef] 
20. Bandi G, Al-Omar O, McLorie GA. Comparison of traditional enterocystoplasty and seromuscular colocystoplasty lined with urothelium. J Pediatr Urol 2007; 3: 484-9. [CrossRef]

21. Lopes FA, Rolim N, Rodrigues T, Canhoto A. Intestinal adenocarcinoma in an augmented ileocystoplasty. BMJ Case Rep 2013; 2013: pii: bcr2013009499.

22. Balachandra B, Swanson PE, Upton MP, Yeh MM. Adenocarcinoma arising in a gastrocystoplasty. J Clin Pathol 2007; 60: 85-7. [CrossRef]

23. Abdelhalim A, Hafez AT. Colovesical fistula: unexpected complication 7 years after augmentation ileocystoplasty. Urology 2013; 82: 1153-5. [CrossRef]

24. Mundy AR, Stephenson TP. "Clam" ileocystoplasty for the treatment of refractory urge incontinence. $\mathrm{Br} J$ Urol 1985; 57: 641-6. [CrossRef]
25. Gurung PM, Attar KH, Abdul-Rahman A, Morris T, Hamid R, Shah PJ. Long-term outcomes of augmentation ileocystoplasty in patients with spinal cord injury: a minimum of 10 years of follow-up. BJU Int 2012; 8: 1236-42. [CrossRef]

26. Liao L, Zhang F, Chen G. Midterm outcomes of protection for upper urinary tract function by augmentation enterocystoplasty in patients with neurogenic bladder. Int Urol Nephrol 2014; 46: 2117-25. [CrossRef]

27. Pope JC 4th, Keating MA, Casale AJ, Rink RC. Augmenting the augmented bladder: treatment of the contractile bowel segment. J Urol 1998; 160: 854-7. [CrossRef]

28. Blaivas JG, Weiss JP, Desai P, Flisser AJ, Stember DS, Stahl PJ. Long-term followup of augmentation enterocystoplasty and continent diversion in patients with benign disease. J Urol 2005; 173: 1631-4. [CrossRef] 